\title{
The Spiral
}

\section{AS A MUSEUM FOR THE FUTURE}

\section{David Anderson}

There is a plethora of new museums which declare themselves institutions for the new century. The Getty Museum in Los Angeles - which could (perhaps unkindly) be described as an ace tea garden with quite a nice museum attached - is one. Another is the Guggenheim in Bilbao. When the new museum in Bilbao opened in 1997, the Director of the Guggenheim, Thomas Krems, said, "That the Museum of the future will no longer resemble the familiar institutional and social form that has quietly and persistently evolved over the past 200 years is a foregone conclusion".

Krems identified a number of factors which will force change. One is the decrease of public funding at a time of rapidly increasing costs. Another is the rising expectations of the public for ever more sophisticated collections, exhibitions, and audience services. Krems said that the expansion and development of museums can no longer be sustained. Museums, he noted, face increasing competition, and a growing unwillingness of governments and the private sector to continue to support museum activities. To this list Krems added the increasing insistence on political relevance, the requirements of multiculturalism, the demands of efficient management, and the risks of exploiting and integrating new technologies. Museums, he said, are facing a cacophony of voices that are frequently at cross - purposes demanding more, with fewer resources. Despite these obstacles Krems decided to go ahead with the expansion of the Guggenheim, and opened its Bilbao satellite (with substantial financial support from the city of Bilbao).

Krems believed that two strategic decisions enabled the Guggenheim to escape the constraints on museum development he had identified. The first was to redefine the art museum (as Krems sees it) by building great buildings, organising great exhibits, and collecting and commissioning great art - an idea, it must be said, that's been around for some time. The second was to attract the largest possible audience, develop secure revenue streams, and balance the books. This is not new either, except that Krems achieved these in the new museum in Bilbao with some flair. There is nothing particularly original, then, about Krem's formula other than its global colonial ambition, and its public facilities appear to be as much an afterthought as in most other art museums. In fact, what is remarkable about the Bilbao Guggenheim as a museum (as op- 
110 posed to the building, which is stunning) is that it conforms resolutely to the traditional model of a twentieth century American art museum. The (somewhat portly) eagle has landed. ${ }^{1}$

This points to a danger for the Spiral. Like the Bilbao Guggenheim, its architecture is dazzlingly original. People will expect the $\mathrm{Mu}-$ seum inside to show the same imagination as its wrapping promises. This is the challenge all institutions which declare themselves to be museums "for the future" must face. On their journey into the unknown, they see around them the bones of earlier projects that failed for want of museological imagination.

Another new institution which seemed, when it still existed, to have articulated a clearer vision for museums for the future was new Metropolis in Amsterdam. Unfortunately, it seems that this institution was too innovative to have survived into the twenty-first century. In 1994, before it opened, its Director Joost Douma wrote a document entitled "Prototyping the 21st Century." In this he suggested that museums have always been expressions of the history of ideas, and underlined the importance of new ideas as a foundation for new institutions. He concluded that rather than merely serving scientists, formal educators, politicians, technicians and industrialists, science centres must be independent agents and should help to steer what he identified as the present intellectual revolution. This he suggested should be done in such a way that as many people as possible gain from it and that their quality of life does not decline, but improves, as part of the transition of Holland from a high-volume to a high-value economy. ${ }^{2}$ As a consequence of the document, new Metropolis developed exhibits that did not present science as a series of facts, but as a set of ideas, activities and skills in which many competences are called into play. It recognised that people rarely relate to science in the same way as a trained scientist, separated from the rest of the world. Instead they see science and technology as intrinsic parts of broader social, political and ethical issues. In other words, science is part of culture, not separate from it. In the same way, the Spiral will aim to make art and design a part of culture.

A number of organisations in the United Kingdom - such as British Telecom, the Design Council, the Royal Society for the Arts' Company of the Future project, the Institute of Education's Classroom of the Future and the Henley Centre, to name but five - have invested systematically in programmes to identify the likely shape of the future. The United Kingdom now has a Future Foundation in London which conducts research on behalf of major companies. According to press reports, the armed forces of the United States formed a large unit which used parapsychology to identify both the current locations and future sources of military threats. So far the success of traditional scientific, social and economic prediction has probably been greater than that of military shamanism (how will we know?), but none has been conspicuously successful. In one area - technological evolution - the researchers have an advantage: the process of development of technological innovation from initial concept to household, corporate or public product takes years, and allows those - such as Microsoft or British Telecom - who invest heavily in technologies for the future an early opportunity to identify some of the dimensions of change in advance of the rest of us.

Two contrasting examples of investment in change may be instructive. One is British Telecom. At MIT's Media Lab in Boston, companies can buy into the Media Lab consortia 


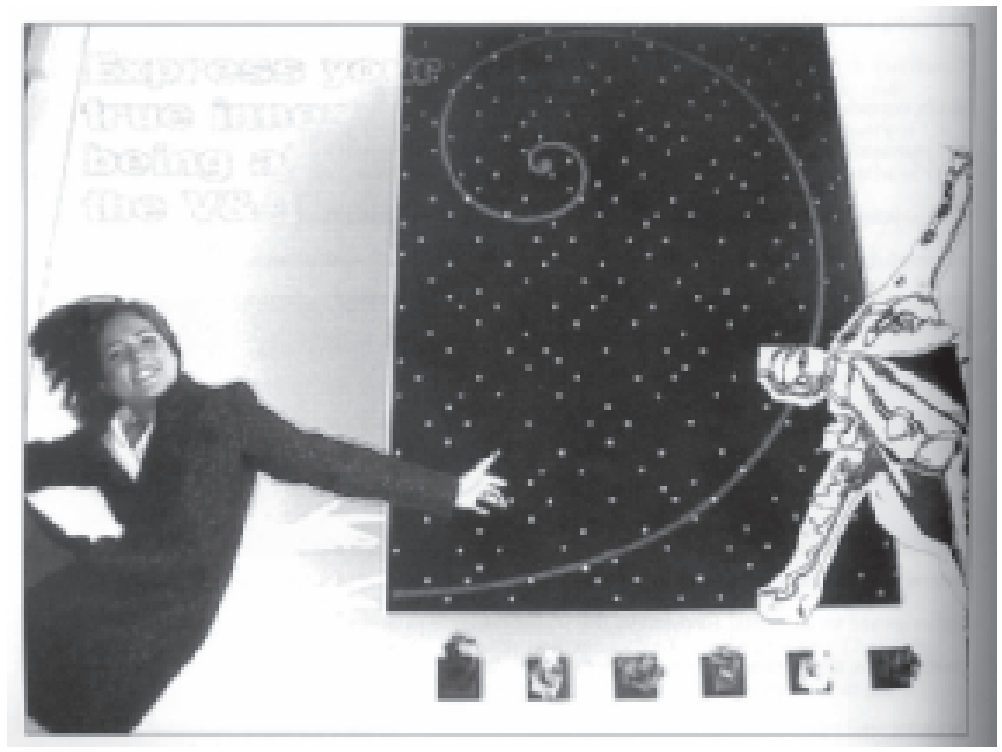

at different levels, allowing them privileged access to and use of innovations. Among the heaviest investors is BT. The company also spends hundreds of millions of pounds each year on a "laboratory" whose experts - engineers, biologists, chemists, even astrophysicists - are dedicated to innovation and development of new communication ideas. One team, the Artificial Life Group, has developed software that grows itself through usage; the "bad" resources die out, the "good" ones survive. The group also pioneered a concept called "information flocking"; 50 or 60 documents are taken off the Internet and allowed to organise themselves into flocks. All the information that is tightly related forms a tight flock; the weakly related material just follows the rest around. The flock forms swirling patterns on the screen. ${ }^{3}$ This is the future developed from the top down. It is real and it will impact upon us all - and will undoubtedly emerge in app- lications in the Spiral. But this is only one way in which the future will be shaped.

The other example is from the bottom up. According to oral tradition, in the early 1970 s a Swedish educator suggested at a long-forgotten conference the idea of the learning society. It was dismissed on the spot by most delegates and seemed destined for oblivion. But over the years, references to the concept started to appear here and there in the literature. By the 1980s, a number of books included the words in their titles and competing definitions emerged. Two decades later, a wide range of organisations in the United Kingdom alone, including the Open University, the Royal Society for the Arts, major companies, and now the Government, have signed up to the idea. The concept of the learning society, whilst an abstraction in itself, now has a powerful influence on public policy and educational practice. No-one invested a pen- 
112 ny in its development, and no-one has copyright on its application. Arguably, the power of a social innovation on the shape of our futures is as great as that of a technological innovation. But we are less sensitised to perceive it - probably to our own disadvantage. In fact, the two may not be separable. The nature of the research by technologists at companies like BT is certainly shaped, consciously or unconsciously, by their concepts of society and its needs; and technology in turn is expanding to an extraordinary extent the social and educational horizons we have available to us.

Major institutions such as the V\&A to a significant degree can make their own future. They do this through deep and long-term investment in the development of their future audience, through the application of resources to research, and through sustained commitment to being a learning organisation one that has an understanding of its purpose in society, and knows clearly where it is now, as well as the direction of its chosen future. Culture is a slow business, and being futureminded is a dynamic process, based on an awareness of both self and society moving through time.

The Spiral is being conceived at a time when the role and function of institutions of all kinds - and most particularly public institutions - is evolving rapidly. The corporation, according to the Japanese academic Fukio Kodama, is changing from "a place for production" to a "place for thinking" ${ }^{4}$ In the UK and many other societies, social and cultural exclusion are seen as critical obstacles in the way of development, and public institutions which do not address this issue are increasingly open to criticism.

Information, like sand, is now the low-skill raw material of the future. Aided by technolo- gy, an information society simply adds more and more sand to the heap. With knowledge, however, the sand can be turned into glass to drink from, enjoy, share or sell. But it requires learning to make a better product to meet changing circumstances. Isolated specialisms and skills are being replaced by flexible and diverse capabilities. Immersive experiences are superceding those gained from objects in our environment. Experiences are available everywhere in the same form in their multiple variety, specific in their response to our personal choice, but not necessarily in their location.

The V\&A in the future will be ubiquitous. The V\&A will not just be "in London"; but will be in London and also in certain respects whenever and wherever you are. It will be a centre that is defined in large part by its peripheries, a "distributed" museum. The Spiral will work centrifugally, unwinding, tensing, making connections. Context and critique will, it is intended, replace unquestioned authority, and there will be plurality of power in the generation of activities, giving public voice to marginalised and specialist groups. Our society presently privileges (to use Henri Lefebvre's terms) "conceived" space over "lived" or felt space, but the Spiral, it is hoped, will value experiences, senses and feelings as highly as concepts.

The Spiral will embrace both high and popular culture (distinctions our audiences think are increasingly irrelevant - we all consume popular culture now). Its concept of excellence will embrace the balance and perfection of everyday life (which itself can be a major cultural achievement) and the diversity of its imperfections. Museums in every country are fortunate in being surrounded by extraordinary cultural wealth: richly distinctive regional and ethnic identities, youth cul- 
tures of enormous vitality, and the capability to produce artefacts of the highest quality. Their exhibits depend as much upon nonmaterial culture - values, ideologies, oral traditions, rituals, ethical standards and beliefs - that are contained within artefacts, and from which they derive their cultural energy. The Spiral will deploy the full range of the contemporary arts to interpret them.

What then, is the unique and distinctive purpose of the Spiral, on behalf of the V\&A? Perhaps it is, through contemporary art and design, to make a difference to the society of which it is part. Embedded within every public institution is a concept of society, and a vision (for good or ill) of society as it could be. The Spiral can offer a model of society that is open, democratic, accountable, inclusive, and an example of the effects of good design on daily life.

Museums are no more a luxury in modern life than literacy, and the Spiral will help to develop a literacy of a kind that is arguably at least as valuable as verbal literacy - the capacity to make meaning, to experience and express what it means to be human, through the arts. It will engage in what William Morris called "the education of desire" - the stimulation of a wish to enhance the quality of our lives. Its goal will not be "good design" but good lives through the medium of art and design. And if it is our job to make a difference, the people we must work most with are those - practitioners, educators and others who will best help us do so. But not always on their terms; those artists who demand that the Spiral is devoted entirely to their own work do not speak for the wider interests of society, which we must represent.

Up to now, most museums have operated on assumptions about culture that are funda- mentally flawed: that culture is made by 113 exhibiting objects in glass cases. There is now overwhelming research evidence that for most people this model does not work. The reality is that culture is made by people, and it is the responsibility of museums to engage them through experiences with objects in a creative process. This, for museums, is the future.

The Spiral will recognise that it is not only experts who have imagination; we are all experts, and we all have talents and experiences that can, if properly encouraged, enrich the lives of others. As John Harvey Jones has written, "To cope with a changing world, we need people of imagination, creativity and vision and with the self-confidence to adapt. That's why I believe so passionately that it doesn't matter precisely where the talents of our people are, so long as it's recognised that everyone has some talent. The job of the educator is to find it". 5 This, in the field of art and design, is our task.

\section{Notes}

1. Thomas Krems, Guggenheim Magazine, New York and Bilbao, October 1997

2. Joost Douma, "Prototyping the Twentieth Century",1994, unpublished document sent to the author by newMetropolis

3. "Hold on, I'll ask", in Design, Spring 1998

4. Fukio Kodama, quoted in John Frow, Cultural Studies and Cultural Value, Oxford, 1995, p95

5. John Harvey Jones, "We must try to aspire more", The Times Educational Supplement, 5 May 1995

\section{David Anderson}

Director of Learning and Interpretation

Adr: Victoria and Albert Museum, South Kensington, London SW7 2RL England

Fax: +4479422193

E-mail:d.anderson@vam.ac.uk 